\title{
STRUKTUR NARATIF SI PITUNG DALAM MEDIA ANIMASI OLEH KASTARI SENTRA DAN YAPS ANIMATION
}

\author{
Arief Ruslan \\ Universitas Budi Luhur \\ Arief.ruslan@budiluhur.ac.id
}

\begin{abstract}
Abstrak
Si Pitung merupakan sastra tradisonal tentang peristiwa bersejarah di abad ke-19 dan menjadi bagian yang paling simbolis oleh masyarakat Betawi. Proyeksi penceritaan si Pitung melalui media audio visual pertama kali diproduksi pada tahun 1930 oleh PT. Halimoen Film (Wong Bersaudara), hanya saja data seluloid film tersebut tidak dapat ditemukan. Cerita si Pitung juga dihadirkan di layar lebar pada tahun 1970-an yang diproduksi oleh PT. Dewi Film. Pada tahun 2018, penceritaan si Pitung diangkat oleh Kastari Sentra dan Yaps Animation melalui animasi. Namun struktur narasi yang dikonstruksi pada media animasi memberikan penceritaan dan yang berbeda pada literatur sebelumnya, sehingga peneliti melihat ada narasi besar yang ingin disampaikan oleh kedua rumah produksi tersebut melalui penceritaan si Pitung dimedia animasi. Penelitian ini bertujuan untuk mengungkapkan struktur naratif si Pitung pada media animasi yang dihadirkan oleh Kastari Sentra dan Yaps Animation. Metodologi penelitian ini adalah kualitatif dengan menggunakan analisis stilistika linguistik. Analisis teks media animasi dikaji melalui struktur naratif yang dihadirkan pada tuturan-tuturan serta visualisasinya. Hasil penelitian menunjukkan bahwa, struktur narasi yang diproduksi oleh Kastari Sentra mengkonstruksi penekanan-penekanan pada bagian cerita yang diadaptasinya, sedangkan Yaps Animation mengkostruksi struktur narasi dengan penambahan penceritaan baru. Faktor ideologis serta kognisi produser memainkan peran yang dihadirkan dalam penceritaan si Pitung dalam media animasi. Sisi-sisi tentang kepahlawanan dan ke-Islaman menjadi narasi besar oleh Kastari Sentra, sedangkan penambahan tokoh Cina dalam struktur narasi yang dihadirkan Yaps Animation menunjukan si Pitung yang lebih nasionalis, sehingga nasionalisme sebagai struktur naraif utamanya.
\end{abstract}

Kata kunci: si Pitung, animasi, struktur naratif, Islam, nasionalisme

\section{PENDAHULUAN}

Sosok si Pitung menggiring kita menuju cerita rakyat, legenda, bahkan historis tentang kejadian fenomenal di Batavia abad ke-19. Cerita si Pitung bukan hanya sebagai cerita rakyat tradisional untuk masyarakat Betawi, tetapi juga melingkupi cerita secara nasional. Bagi masyarakat Indonesia, tokoh si Pitung masih melekat secara kolektif dalam ingatan sebagai pahlawan masyarakat Betawi, yang mempunyai nilai-nilai tentang perjuangan, kesantunan, 
kegigihan, kepedulian, serta kerja sama. Hal ini didasari dari cerita lisan secara turun temurun (Yanti, 2016).

Repetoar petualangan si Pitung pun menjadi bentuk yang populer pada para pencerita Betawi. Aksi-aksi si Pitung ditampilkan pada beberapa sastra seperti dalam sebuah fragmen, Lenong (Knorr, 2007; Van Till, 2008), dan juga melalui balada yang dimainkan pada Rancag "si Pitung" (Grijns, 1976), menceritakan sebagai tokoh yang mempunyai "keberanian" yang diabadikan dalam wujud "roh". Dalam rancag yang ditampilkan melalui gambang, syair, maupun pantun, menceritakan si Pitung sebagai pahlawan Betawi yang merampok penjilat rakyat, yaitu Haji Sapiudin, dan berakhir menjadi buron serta kematian si Pitung di tangan polisi atau seseorang dari Tanah Abang.

Dalam kacamata kolonial, munculnya nama si Pitung seringkali disebut jago atau seseorang pahlawan dan pembela rakyat atas kesewenang-wenangan mandor, yang ditunjuk tuan tanah terhadap para petani di Batavia yang menyewakan tanahnya. Ancaman para jago, khususnya terhadap para Tuan Tanah kaya ini menyebabkan keresahan-keresahan di beberapa tempat, ditambah semakin merebaknya gerombolan pencuri di daerah tersebut. Walaupun tidak dianggap sebagai permasalahan yang serius bagi Belanda, tetapi mereka tetap mengirimkan perwira-perwira distrik (kommandant) dan kepala kampung untuk mengontrol orang-orang Indonesia .

Perampokan sepertinya menjadi salah satu aksi besar yang dilakukan oleh si Pitung. Darmadini (1993) dalam tesis yang melihat sastra lisan, bahwa Haji Sapiudin dirampok dan dikuras harta kekayaannya dan hasil perampokannya tersebut dibagikan ke rakyat-rakyat miskin. Alih-alih sebagai pahlawan untuk rakyat kecil yang memberikan hasil rampasannya ke masyarakat miskin ternyata ditepis sedemikian rupa. Pembuktian pembagian hasil rampokan kepada rakyat miskin tersebut tidak mempunyai bukti yang otentik. Selain itu, banyak kabar beredar bahwa pembagian hasil disumbangkan ke masjid-masjid, dan ini pun hanya rumor, hal tersebut dikarenakan pada saat itu masjid hanya ada di Pekojoan, Luar Batang, dan Kampung Sawah. Tentu saja cerita pendermaan rampokan ke masjid-masjid sekali lagi tidak ada pembuktian yang kuat.

Bagi beberapa tokoh Betawi, penceritaan si Pitung sebagai perampok tentu perlu dikaji. Pandangan-pandangan tentang aksi tersebut tentunya melihat dalam kondisi kolonial pada saat itu. Tokoh ini merupakan pahlawan yang membumi dan cinta kepada masyarakat sekitar, apalagi pada saat itu banyaknya tuan tanah yang mengambil hak-hak pribumi untuk kepentingan pribadi 
bahkan kolonial. Yahya Andi Saputra (2019), sebagai ketua Lembaga Kebudayaan Betawi mengatakan bahwa Pitung merupakan salah satu tokoh lokal yang berani melawan ketidak adilan pada masa kolonial, dan sebagai tokoh yang mengambil kembali hak-hak masyarakat. la juga melanjutkan, bahwa si Pitung merupakan produk agensi, hal ini diterangkan bahwa si Pitung sebagai sosok yang misterius pada saat itu.

Sejak film yang bercerita tentang aksi-aksi si Pitung diterbitkan tahun 1931 hingga 1977 , film yang menghadirkan tokoh legendaris Betawi ini mulai menghilang. Munculnya cerita si Pitung kembali eksis di tahun 2018 melalui animasi yang diproduksi oleh dua rumah produksi, yaitu Kastari Sentra dan Yaps Animation. Di dalam media Youtube, kedua rumah produksi ini mempunyai kanal khusus yang memberikan cerita edukasi tentang dongeng dan sejarah.

Struktur naratif yang diangkat tentang cerita si Pitung oleh kedua rumah produksi ini merupakan hal yang menarik bagi peneliti untuk dikaji. Hal ini dikarenakan, melihat histrografi kedua belah pihak yang berbeda. Penerjemahan kembali (transformasi) cerita serta nilai-nilai cerita si Pitung ini pun mengalami penambahan, pengurangan, dan modifikasi cerita menjadi alat untuk tujuan tertentu. Perbedaan ini menjadi landasan bagaimana mereka menangkap, memahami, dan memaknai setiap gaya cerita yang sudah lama menjadi warisan diterjemahkan dan direkontruksi.

\section{METODOLOGI PENELITIAN}

Penelitian ini menggunakan paradigma konstruktivisme dengan penafsiran konstruktivis dideskripsikan sebagai intepretivisme, yakni melihat dan memahami individu-individu berusaha memahami dunia tempat mereka hidup dan bekerja. Teknik Analisis dan Penyajian data dalam penelitian kualitatif dimulai dengan menyiapkan dan mengorganisasi data, yang kemudian mereduksi data tersebut menjadi tema melalui proses pengodean dan peringkasan kode. Selanjutnya, menyajikan data dalam bentuk bagan, tabel, atau pembahasan (Creswell, 2014).

Metode penelitian ini mengambil narasi si Pitung dalam bentuk animasi yang diproduksi oleh Kastari Sentra dan Yaps Animation. Struktur naratif dianalisis menggunakan teori stilistika linguistik yang menyajikan studi singkat tentang struktur transaksional dialog sebagai tindakan narasi dengan komponennya, dan bukti kekuasaan serta penghormatan dalam pengelolaan bahasa. Dengan memeriksa sepotong teks sastra menggunakan tiga metode penyajian yang saling melengkapi. Yang pertama adalah parafrase, kedua adalah komentar, atau eksposisi baris demi baris, dan yang ketiga adalah sinopsis ditulis dalam hal pragmatik (Carter \& Simpson, 2005). 


\section{HASIL DAN PEMBAHASAN}

Struktur narasi yang produksi oleh Kastari Sentra dan Yaps Animation dalam cerita si Pitung mengalami trasformasi cerita. Melalui adaptasi dari bagian-bagian sastra tradisional diproduksi sedemikan rupa mentransformasikan identitas sebuah cerita tersebut. Proses adaptasi cerita dihadirkan dengan cara merekonstruksi sastra tradisional dan dikonstruksi dengan bentuk yang sesuai dengan gagasasan yang baru. Gagasan-gagasan inilah yang mentransformasikan sebuah cerita baru (kontemporer) sebagai landasan-landasan sang kreatornya.

Apa yang diungkapkan oleh Carlson (1997) bahwa satra tradisional dapat menjadi medium aktivitas kolektif manusia dalam interaksi sosial sebagai sarana kesadaran mentransformasikan identitas, memang menjadi bagian yang penting untuk melihat gagasangagasan pembuatnya. Tentu saja, dengan memadukan masa lalu dan masa kini tidak selalu fiksi atau menciptakan ambivalensi. Melengkapi dan menyempurnakan sastra memang mengubah literasi yang diwariskan secara bergenerasi, tetapi esensi dalam sastra kontemporer diciptakan untuk mengungkap kondisi-kondisi manusia itu sendiri.

Sekalipun sastra tradisional yang diwariskan melalui tuturan-tuturan seringkali dianggap mitos, tetapi mitos ini memiliki kemampuan penting untuk menyatukan masyarakat dengan menjelaskan dunia yang berada di luar wilayahnya. Menciptakan narasi sastra tradisional melalui film adalah sebuah tantangan karena melibatkan pengumpulan potongan-potongan masa lalu dari cerita rakyat, dari mulut ke mulut, tradisi masyarakat, dan menyatukannya untuk menciptakan citra dan narasi yang bermakna. Oleh karena itu hal tersebut dapat dianggap sebagai konseptualisasi, rekreasi dan diseminasi melalui pola linier atas kumpulan kejadian sosial, politik, budaya dan ekonomi dari masa lalu untuk menciptakan memori untuk generasi sekarang (Raj \& Sreekumar, 2013).

Melalui penelusuran serta peredusian struktur narasi si Pitung yang dihadirkan pada sastra tradisional hingga video animasi yang dipoduksi oleh Kastari Sentra dan Yaps Animation. Peneliti mengambil penceritaan si Pitung yakni:

1. Sastra tradisional (ST) yang melingkupi pantun dan syair yang ditulis serta ditampilkan pada peragaan budaya yang dihadirkan pada rancak dan gamang kromong.

2. Film nasional (FL) tahun 1971-1972 yang diproduksi oleh PT. Dewi Film. 
3. Data Belanda (DB) yang melingkupi berita-berita yang dihadirkan pada media massa kolonial serta para penulis dan peneliti tentang peristiwa si Pitung serta kejadian yang berhubungan pada cerita tersebut di wilayah residen Ommenladen, Batavia.

4. Buku-buku cerita (BK) tentng si Pitung yang telah diterbitkan dan disimpan pada Dinas Kebudayaan Propinsi DKI Jakarta. Buku cerita ini mempunyai tiga terjemahan cerita, yakni oleh Budiaman yang berjudul Folklor Betawi tahun 1979 (cetakan pertama), oleh Rahmat Ali yang berjudul Cerita Rakyat Betawi tahun 1993, dan Dinas Kebudayaan DKI dengan judul Legenda Jakarta tahun 2000.

5. Buku karya Iwan Mahmoed Al-Fattah (AL) yang berjudul Pitung: Pituan Pitulung tahun 2017.

6. Video animasi yang berjudul Dongen Betawi yang diproduksi oleh Kastari Sentra (KS) tahun 2018.

7. Video animasi yang berjudul Kisah si Pitung dari DKI Jakarta yang diproduksi oleh Yaps Animation (YA) tahun 2018.

Tabel 1. Bentuk Adaptasi Cerita si Pitung Oleh Kastari Sentra dan Yaps Animation

\begin{tabular}{|l|l|c|c|c|c|c|c|c|}
\hline No & \multicolumn{1}{|c|}{ Struktur Narasi } & ST & FL & DB & BK & AL & KS & YA \\
\hline 1. & Tokoh pahlawan Jakarta & - & - & - & - & $\mathrm{V}$ & $\mathrm{V}$ & - \\
\hline 2. & Mati Dengan Peluru Emas & - & $\mathrm{V}$ & - & - & - & $\mathrm{V}$ & - \\
\hline 3. & Pitung seorang santri & - & - & - & $\mathrm{V}$ & $\mathrm{V}$ & $\mathrm{V}$ & - \\
\hline 4. & Dikhianati & - & $\mathrm{V}$ & - & $\mathrm{V}$ & - & $\mathrm{V}$ & - \\
\hline 5. & Pitung orang muslim yang saleh & - & $\mathrm{V}$ & - & $\mathrm{V}$ & $\mathrm{V}$ & $\mathrm{V}$ & - \\
\hline 6. & Kemampuan kebal & $\mathrm{V}$ & $\mathrm{V}$ & $\mathrm{V}$ & $\mathrm{V}$ & - & $\mathrm{V}$ & - \\
\hline 7. & Seorang jagoan/jago & $\mathrm{V}$ & $\mathrm{V}$ & $\mathrm{V}$ & $\mathrm{V}$ & $\mathrm{V}$ & $\mathrm{V}$ & $\mathrm{V}$ \\
\hline 8. & Mempunyai kemampuan silat & $\mathrm{V}$ & $\mathrm{V}$ & $\mathrm{V}$ & $\mathrm{V}$ & $\mathrm{V}$ & $\mathrm{V}$ & $\mathrm{V}$ \\
\hline 9. & Merampok & $\mathrm{V}$ & $\mathrm{V}$ & $\mathrm{V}$ & $\mathrm{V}$ & $\mathrm{V}$ & $\mathrm{V}$ & $\mathrm{V}$ \\
\hline 10. & Pembela rakyat kecil & $\mathrm{V}$ & $\mathrm{V}$ & $\mathrm{V}$ & $\mathrm{V}$ & $\mathrm{V}$ & $\mathrm{V}$ & $\mathrm{V}$ \\
\hline 11. & Menjadi buronan & $\mathrm{V}$ & $\mathrm{V}$ & $\mathrm{V}$ & $\mathrm{V}$ & - & $\mathrm{V}$ & $\mathrm{V}$ \\
\hline 12. & Merampok pejabat belanda & - & - & - & - & - & $\mathrm{V}$ & $\mathrm{V}$ \\
\hline 13. & Tertangkap & $\mathrm{V}$ & $\mathrm{V}$ & $\mathrm{V}$ & $\mathrm{V}$ & - & - & $\mathrm{V}$ \\
\hline 14. & Berteman dengan orang Cina & - & $\mathrm{V}$ & - & - & $\mathrm{V}$ & - & $\mathrm{V}$ \\
\hline 15. & Pitung menolong orang Cina & - & $\mathrm{V}$ & - & - & - & - & $\mathrm{V}$ \\
\hline 16. & Pitung ditolong oleh orang Cina & - & $\mathrm{V}$ & - & - & $\mathrm{V}$ & - & $\mathrm{V}$ \\
\hline 17. & Merampok tuan tanah & $\mathrm{V}$ & $\mathrm{V}$ & $\mathrm{V}$ & $\mathrm{V}$ & $\mathrm{V}$ & - & - \\
\hline 18. & Memiliki jimat & $\mathrm{V}$ & $\mathrm{V}$ & $\mathrm{V}$ & $\mathrm{V}$ & - & - & - \\
\hline
\end{tabular}

Pada tabel di atas, KS menampilkan 11 (sebelas) poin struktur cerita yang diadaptasi pada literatur sebelumnya, ditambah 1 (satu) poin cerita yang berbeda. Melalui peredusian 
struktrur narasi, dapat diasumsikan bahwa penggunaan literatur dalam video animasi yang ditayangkan oleh KS mengadaptasi BK, walaupun kemiripan cerita FL juga mendekati pada struktur narasi KS, tetapi pada bagian 13,14,15,16, 17, dan 18, KS tidak menampilkan apa yang dihadirkan oleh BK. Sehingga bentuk struktur narasi yang menjadi dasar penceritaan adalah BK.

Beberapa bagian cerita memang terlihat saling berbeda satu sama lain, tetapi secara konvensional cerita aksi Pitung agaknya mempunyai kesepakatan yang masih terjalin dari beberapa literatur ST, FL, DB, dan BK seperti Pitung sebagai pembela rakyat, menjadi buronan, merampok tuan tanah, kemampuan kebal, mempunyai jimat, dan mati dengan peluru emas. Kesepakatan lain yang juga tidak kalah penting adalah pada bagian cerita perampokan kepada para pejabat Belanda juga tidak dihadirkan pada literatur tersebut.

Begitu pula KS dan YA yang memberikan perbedaan pandangan dalam struktur narasi melalui video animasinya. Kesamaan-kesamaan cerita hanya hadir pada beberapa bagian, yakni komponen si Pitung menjadi pembela rakyat, buronan, dan merampok pejabat Belanda. Kesepakatan lain juga terjadi dengan tidak menghadirkan bagian perampokan kepada tuan tanah Batavia serta penggunaan jimat oleh si Pitung.

Struktur narasi yang dikonstruksi oleh KS agaknya beradaptasi dengan cara inter-subjektif pada literatur terdahulunya. Adaptasi bagian-bagian cerita tersebut dipilah dan dinegosisasikan untuk menyesuaikan narasi yang dihadirkan. BK dan FL menjadi rujukan yang cukup dominan dalam struktur penceritaan KS. Salah satu yang paling menonjol seperti pada narsi pertemuan si Pitung degan para perampok. Tuturan, gaya bahasa, serta visual yang ditampilkan sangat sesuai dengan keduanya. Walaupun terihat adaptasi melalui literatur BK dan FL yang cukup dominan, tetapi pada bagian tertentu masih mengadaptasi gaya narasi yang lain yakni BK.

Struktur narasi yang dihadirkan oleh KS sangat mendekati dengan penceritaanpenceritaan sebelumnya, atau dapat dikatakan sangat monoton dan tidak banyak berubah. Walaupun demikian, bentuk adaptasi hanya diambil dengan bebeberapa bagian yang sesuai dengan penceritaan yang konvensional, tetapi pada beberapa bagian ditransformasikan atas penyesuaian segmentasi, pasar, serta kebutuhan perusahaan.

Sedangkan struktur narasi yang dihadirkan oleh YA dikonstruksi sangat berbeda jauh dengan literatur sebelumnya, khususnya pada bagian personifikasi. Pitung yang sebagai tokoh muslim tidak dihadirkan pada penceritaan tersebut. Adaptasi yang memainkan peranan penting di sini adalah, bentuk peristiwa kedekatannya kepada masyarakat miskin. Seorang jago atau jagoan yang mempunyai kemampuan silat dijelaskan dengan cukup singkat. Yang menjadi 
landasan utama bentuk adaptasi yang peneliti anggap eksklusif adalah pada bagian nomor 14, 15, dan 16, yaitu interaksi Pitung dengan tokoh Cina. Ekslusif ini dikarenakan hanya FL saja yang menampilkan tentang kedekatan antar tokoh tersebut.

Struktur narasi ini cenderung menceritakan tentang hubungan si Pitung dengan masyarakat Cina. Penggunaan tokoh ketiga yaitu nyak Ling-Ling yang munul pada beberapa babak mengindikasikan tokoh Cina juga ikut andil dalam sastra tradisional masayarakat Betawi yang populer ini. Gagasan tersebut terbentuk atas bagian tentang ke-nasionalisme atas harapan sang produser. Setidaknya, penceritaan tentang tokoh Cina pada narasi si Pitung memang dihadirkan pada film era tahun 70an, tetapi penceritaan ini sangat sedikit dan seringkali tokoh Cina berperan sebagai tuan tanah yang kejam dan suka berfoya-foya.YP mengkonstruksi strukutur narasi yang lebih baru dan berbeda dengan penceritaan konvensional, mungkin saja bentuk penceritaan ini ingin menunjukan tentang jalinan tokoh Cina terhadap tokoh legenda Betawi sebagai bagian dari kehidupan mereka.

Cerita adalah mekanisme di mana anggota sebuah komunitas menghasilkan sekelompok kenangan bersama yang menjadi fondasinya keberadaan mereka dan pembangunan yang berkelanjutan dari dunia bersama. si Pitung sudah menjadi tokoh sentral dalam penceritaanpenceritaan masayarakat Betawi. Sebuah "story" yang melegenda diwariskan secara lisan tidak terlepas dari perubahan-perubahan cerita. Transformasi bukan hanya terjadi dalam bentuk struktur yang naratif, melainkan stuktur yang lebih tinggi seperti indentitas bahkan ke bagian diskursif sosial imajiner.

Fungsi bahasa, baik itu bahasa penutur asli maupun bahasa pengguna bahasa menyampaikan keinginan pembicara dan niat. Pemilihan bahasa diatur oleh bentuk pertimbangan fungsi bahasa yang seharusnya dilakukan oleh ujaran baik struktur fisik ujaran, uga situasi di mana tuturan akan digunakan. Artinya, kalimat diucapkan untuk tujuan tertentu. Dan kegiatan verbal ini adalah diakui demikian oleh lawan bicaranya, karena tata cara yang diatur melalui prosedur sintaksis, semantik, dan pragmatis. Peraturan ini tidak mengurangi kemampuan berbahasa yang dinamis, produktif, kreatif, dan terbuka. Penutur yang ingin mengartikulasikan fungsi linguistik apa pun mungkin sama kreatifnya seperti yang mereka inginkan (Kaburise, 2011).

Melalui rekonstruksi cerita dengan beberapa konstruksi pada bagian-bagian cerita baru yang dihadirkan menjadi cerita yang lebih kontemporer, mentransformasikan gagasan untuk membentuk opini serta perspektif penonton menyandingkan dengan keadaan sosial, budaya, politik, dan agama saat ini. Sebagaimana pandangan Fowler (1981, cited as Studer, 2008) bahwa 
Struktur linguistik dapat digunakan untuk mensistematisasikan, mengubah, dan sering kali mengaburkan realitas untuk mengatur ide dengan mengklasifikasikan dan membuat peringkat orang, peristiwa, dan objek untuk menegaskan status institusional atau pribadi.

Bentuk transformasi pada struktur narasi yang dihadirkan oleh Kastari Sentra dan Yaps Animation sebagai berikut:

Tabel 2. Bentuk Transformasi Stilistika si Pitung Oleh Kastari Sentra dan Yaps Animation

\begin{tabular}{|c|c|c|}
\hline \multirow{2}{*}{ Babak Narasi } & \multicolumn{2}{|c|}{ Transformasi Stilistika } \\
\hline & Kastari Sentra & Yaps Animation \\
\hline Pembuka/prologue & $\begin{array}{l}\text { Penambahan: } \\
\text { Jakarta sebagai Betawi }\end{array}$ & $\frac{\text { Pengurangan: }}{\text { Rawabelong }}$ \\
\hline Tokoh dan penokohan & $\begin{array}{l}\text { Penambahan: } \\
\text { Santri, Pondok pesantren, } \\
\text { bekepribadian kuat, dikirim oleh } \\
\text { orang tua } \\
\text { Pengurangan: } \\
\begin{array}{l}\text { Inisiatif belajar ke rumah haji } \\
\text { Naipin }\end{array}\end{array}$ & $\begin{array}{l}\text { Penambahan: } \\
\text { Nyak Ling-Ling (tokoh Cina) } \\
\text { Pengurangan: } \\
\text { Muslim, belajar mengaji, Haji } \\
\text { Naipin, orang tua si Pitung }\end{array}$ \\
\hline Aksi & $\begin{array}{l}\text { Penambahan: } \\
\text { Merampok pejabat Belanda } \\
\text { Pengurangan: } \\
\text { Tertangkap (dipenjara), } \\
\text { melarikan diri, merampok Tuan } \\
\text { tanah pribumi, tuan tanah Cina }\end{array}$ & $\begin{array}{l}\text { Penambahan: } \\
\text { Penangkapan ibu si Pitung, } \\
\text { mengambil karung beras, } \\
\text { memberikan hasil rampokan ke } \\
\text { tokoh Cina } \\
\text { Pengurangan: } \\
\text { Tuan tanah pribumi, Tuan tanah } \\
\text { Cina }\end{array}$ \\
\hline Akhir & $\begin{array}{l}\text { Penambahan: } \\
\text { Penembakan oleh tentara } \\
\text { Belanda } \\
\text { Pengurangan: } \\
\text { Jimat }\end{array}$ & $\begin{array}{l}\text { Penambahan: } \\
\text { Arwah, mengalahkan Belanda, } \\
\text { Belanda tobat, Belanda } \\
\text { memberikan hasil rampasannya, si } \\
\text { Pitung memberikan ketentraman } \\
\text { masyarakat. } \\
\text { Pengurangan: } \\
\text { Peluru emas, Jimat }\end{array}$ \\
\hline
\end{tabular}


Pada babak pembuka (prologue) transformasi stilistika pada penceritaan si Pitung oleh Kastari Sentra terjadi penambahan tuturan (lokusi). Bentuk penambahan tersebut adalah kalimat Jakarta yang disandingkan sebagai bagian Betawi. Kalimat ini menjadi bagian pusat kalimat pernyataan kreator sebagai pandangan identitas tokoh berada. Penggunaan tuturan tersebut memberikan konsep dasar tujuan (ilokusi) sang konstruktor untuk mengukuhkan tentang fenomena kebangsaan tokoh si Pitung. Makna serta gagasan yang ingin digapai sebagai capaian perlokusi naratif agaknya menampilkan sosok kepahlawanan dari Jakarta yang menjadi utama narasi.

Di babak tokoh penokohan, setidaknya ada beberapa penambahan tuturan seperti kata santri, pondok pesantren, bekepribadian kuat, dan bagian si Pitung yang dikirim oleh orang tuanya untuk belajar mengaji di pondok pesantren haji Naipin sebagai tujuan (perlokusi) naratif untuk memengaruhi kahalayaknya. Pengurangan stilistika yang terjadi pada babak ini adalah penceritaan si Pitung yang sebenarnya inisiatif (berkemauan sendiri) ke rumah haji Naipin untuk mendalami agamanya dengan belajar mengaji.

Transformasi yang hadir pada babak aksi terjadi penambahan tuturan yang lebih spesifik, yaitu pejabat Belanda. Beberapa penghilangan cerita yang dihadirkan pada literatur sebelumnya adalah si Pitung tertangkap dan dipenjara, melarikan diri dari penjara, perampokan terhadap tuan tanah pribumi dan tuan tanah Cina. Di babak akhir penambahan cerita dibubuhi atas penembakan oleh tentara Belanda, sedangkan pengurangan cerita adalah tentang jimat seperti pemakaian jimat, pelemparan telur busuk, atau pemotongan rambut pada versi yang lain.

Transformasi yang terjadi pada struktur narasi oleh Yaps Animation juga terjadi pada setiap babak penceritaan. Pada babak pembuka (prologue) terjadi pengurangan tentang penceritaan si Pitung sebagai anak Rawabelong dan lebih cenderung menkankan sebagai tokoh Betawi. Pada babak tokoh dan penokohan, penambahan tokoh baru yaitu Nyak Ling-Ling sebagai orang Cina dihadirkan dalam penceritaan. Pengurangan stilistika pada babak ini cenderung berhubungan dengan personidikasi si Pitung yang religius. Pengurangan tokoh muslim, tentang kejadian belajar mengaji ke sebuat rumah haji Naipin dan tentang orang tua si Pitung tidak dihadirkan.

Pada babak aksi penambahan cerita dihadirkan tentang penangkapan ibu si Pitung oleh pihak Belanda. Aksi perampokan dihadirkan dengan cara yang lebih sederhana dan halus, yaitu mengambil beberapa karung beras oleh si Pitung di sebuah gudang kepunyaan tentara Belanda. Penambahan lainnya adalah pemberian hasil rampokan si Pitung kepada tokoh Cina yang 
diperankan oleh nyak Ling-Ling. Bentuk pengurangan pada penceritaan di babak ini adalah perampokan kepada tuan tanah pribumi dan tuan tanah Cina.

Penambahan di babak akhir adalah tentang penceritaan si Pitung yang menjadi arwah setelah kematiannya oleh pihak tentara Belanda. Arwah ini menjadi pertunjukan dalam aksi selanjutnya tokoh si Pitung, yaitu mengemban kewajibannya dalam mengalahkan tokoh Belanda. Penambahan lainnya yakni dengan kekalahannya, Belanda bertobat dan memberikan semua hasil rampasan kepada rakyat. Selanjutnya penambahan stilistika dihadirkan dengan menekankan bahwa si Pitung memberikan ketentraman kepada masyarakat yang telah dijajah oleh pihak Belanda.

\section{SIMPULAN}

Sastra tradisional yang diwariskan secara lisan sangat sulit dijaga dan dicari keasliannya sehingga membangun komoditas sastrawan kontemporer. Interpretasi serta opini juga tidak dapat dihindarkan tidak menjadikan hal yang salah dalam penafsiran. Sastra tradisional seringkali diceritakan kembali dengan media-media dan gaya cerita baru dengan cara menghibur, berkomedi, berkebudayaan, atau dengan medium historis yang berpendidikan. Sehingga dengan penceritaan kembali yang kontemporer bukan hanya menjadi ruang pewarisan kekiniaian, juga memberikan wawasan moral, identifikasi budaya dan kebudayaan, serta ideologis sang satrawan.

Tidak sedikit film-film populer mengadaptasi dari cerita-cerita tradisional yang dihadirkan secara bergenerasi. Hal tersebut sebagai bentuk menghidupkan dan mengabadikan naratif kebudayaan masyarakat. Carlson (1997) melihat naratif kontemporer yang dianggap "berkualitas" selalu mengadaptasi sastra-sastsa, epos alkitab, sejarah, bahkan cerita fiksi (fairy tales) sebagai bagian dari budaya bangsa yang dapat diterima segenap kahalayak. Namun, praktik distribusi naratif kontemporer acapkali mengkonstruksi tatanan baru yang dilegitimasikan dengan gagasangagasan sang pembuatnya.

Penyesuaian cerita dihadirkan dengan bentuk bahasa baik tuturan (lokusi) hingga pemilihan kalimat dalam penceritaan. Stilistika berproses bukan hanya terjadi perubahan tuturan akibat adanya relasi antara adaptasi serta transformasi yang diproduksi oleh penaskah serta produser, melainkan pula terhadap keterangan-keterangan untuk tujuan dan maksud tertentu (ilokusi), serta memengaruhi khalayak (perlokusi) tentang narasi tersebut. Sehingga struktur narasi menjadi berkembang atas pembentukan pada sistem produksi yang dilakukan oleh kedua peran para kreatornya. 


\section{REFERENSI}

Carlson, J. 1997. Vilification of Identity and the Exilic Narrative: The Illustrated Pied Piper Story. Journal of Visual Literacy, $17(2), \quad$ 89-112. https://doi.org/10.1080/23796529.1997.11674523

Carter, R., \& Simpson, P. 2005. Phatic Communion and Fictional Dialogue \& Politeness Phenomena in Ionesco's The Lesson. In Language, Discourse and Literature.

Creswell. W, J. 2014. Penelitian Kualitatif \& Desain Riset: Memilih di Antara Lima Pendekatan. Edisi Bahasa Indonesia 2014. Yogyakarta: Pustaka Pelajar.

Grijns, C. D. 1976. Lenong in the environs of Jakarta : a report. Archipel, 121, 175-202. https://doi.org/10.3406/arch.1976.1301

Kaburise, P. 2011. Speech act theory and and Communication

Knorr, J. 2007. Creole Identity And PostcolonialNation-Building Examples From Indonesia And Sierra Leone. Série Antropologia. Vol. 416.

Raj, S. J., \& Sreekumar, R. 2013. Colonial rebels in Indian cinema: narratives, ideology and popular culture. Journal of Creative Communications, 82-3, 251-263.

Studer, P. 2008. Historical Corpus Stylistics: Media, Technology and Change. 280.

Van Till, M. 2018. Batavia Kala Malam: Polisi, Bandit, dan Senjata Api. Masup Jakarta. Depok.

Yanti, N. 2016, Kajian Bandingan Legenda Robin Hood dan Legenda si Pitung, Jurnal Kiprah, Hal 27-45 